\title{
Pensions and low sodium salt: a qualitative evaluation of a new strategy for managing hypertension in rural South Africa.
}

Peter Lloyd-Sherlock [corresponding author]

School of International Development, University of East Anglia, Norwich, NR4 7TJ, UK.

p.lloyd-sherlock@uea.ac.uk

Fransesc Xavier Gómez-Olivé

MRC/Wits Rural Public Health and Health Transitions Research Unit (Agincourt), School of Public Health, Faculty of Health Sciences, University of the Witwatersrand, Johannesburg, South Africa.

Harvard Center for Population and Development Studies, Harvard University, Cambridge, MA

INDEPTH Network, Accra, Ghana

F.Gomez-OliveCasas@wits.ac.za

Sizzy Ngobeni

MRC/Wits Rural Public Health and Health Transitions Research Unit (Agincourt), School of Public Health, Faculty of Health Sciences, University of the Witwatersrand, Johannesburg, South Africa.

\section{Sizzy.ngobeni@wits.ac.uk}

Ryan G. Wagner

MRC/Wits Rural Public Health and Health Transitions Research Unit (Agincourt), School of Public Health, Faculty of Health Sciences, University of the Witwatersrand, Johannesburg, South Africa.

\section{ryan.wagner@wits.ac.uk}

Stephen Tollman

MRC/Wits Rural Public Health and Health Transitions Research Unit (Agincourt), School of Public Health, Faculty of Health Sciences, University of the Witwatersrand, Johannesburg, South Africa.

INDEPTH Network, Accra, Ghana

Stephen.tollman@wits.ac.uk 


\begin{abstract}
.
Background

This paper describes a pilot study to assess the feasibility of a novel intervention to improve the management of hypertension among older people in rural South Africa. Older South Africans have the highest rates of uncontrolled hypertension recorded for any country. Notably, South Africa has a widely-available old age grant (pension), which is delivered on a monthly basis to citizens living in rural villages.

Methods

We assessed the feasibility of engaging with older people at the point of pension delivery in the Agincourt sub-district of Mpumalanga Province. This included providing information about hypertension, measuring blood pressure, referral to primary care services, and providing a monthly supply of low sodium salt. We recruited 20 people aged 60 and over to participate in the pilot intervention, which was conducted over three months in two villages. Towards the end of the intervention, we conducted focus groups with study participants and held a meeting with local stakeholders, including the district health office and the state social security agency.

Results

The pilot study demonstrated (i) Sustained engagement with the original 20 participants. Of these, 19 continued to participate in the intervention during subsequent monthly pension days. (ii) A high level of acceptance of the low sodium salt product, reflected in repeat usage and comments made in the focus groups. (iii) Strong support for the intervention and a willingness to collaborate by local stakeholders. (iv) A perception among participants that symptoms they associated with hypertension had abated. This is supported by blood pressure readings made over the three months of follow-up.

Conclusion
\end{abstract}

Though limited in scope, this pilot study provided evidence of the feasibility of the intervention and justification for it to be tested on a larger and more robust basis.

\title{
Keywords.
}

Hypertension, older people, pensions, South Africa, Agincourt, intervention 


\section{Background.}

This paper describes a small pilot study, which assesses the feasibility of implementing a novel intervention to improve the management of hypertension among older people in rural South Africa through the provision of low sodium salt and regular monitoring of blood pressure. Hypertension is the most important cause of cardiovascular disease in subSaharan Africa, which is expected to nearly double between 2015 and 2030 [1]. Poor diet, particularly high sodium intake, is an important risk factor for hypertension [2, 3]. Encouraging the use of low sodium salt has been demonstrated to be an effective intervention for managing hypertension among African populations [4]. The product increases potassium intake, which could lead to undesired side-effects. However, available research for African populations shows that intake of potassium is generally below recommended levels [4].

Recent studies report that the prevalence of hypertension among adults aged 50 years and over in South Africa was 78 per cent in 2010 [5]. Average salt intake among South African adults is substantially higher than the recommended $4-6 \mathrm{~g} /$ day recommended by the World Health Organization [6]. While the beneficial effect of reduced sodium consumption is well-understood, a key challenge (as with many aspects of public health) is to translate this epidemiological insight into changed behaviour among specific populations. Older people living in rural South Africa represent a "difficult to reach" population for several reasons. These include the limited availability of formal health services and limited engagement with those services that do exist [7].

The intervention was conducted in the Agincourt Health and Socio-demographic Surveillance System (HDSS), a rural setting in north eastern South Africa, which is overseen by the MRC/Wits Agincourt Research Unit (www.agincourt.co.za). The Agincourt HDSS has been collecting annual data since 1992 from a population of currently 115,000 . Specific surveys of older people's health have been conducted in the HDSS collaboratively with the World Health Organisation [8]. Data from the Agincourt HDSS show that in 2013, the district contained 5,329 people aged 60 and over, 6.6 per cent of its total population.

Agincourt is a former "Bantustan" area: territory set aside for the black population during the Apartheid era. Typical of such areas, basic health and education facilities and living standards are poor compared to urban and rural non-Bantustan parts of the country. Since the political transition in 1992 there have been significant improvements to service provision, but the legacy of Apartheid remains in terms of an older population with little formal education or lifetime experience of engaging with formal health care providers [9]. The public health system in the sub-district consists of seven clinics and two health centres, with three district hospitals situated between 25 and $45 \mathrm{~km}$ from the study site [8]. A survey of service provision and utilisation conducted in 2006 found that 60 per cent of men and 52 per cent of women aged 50 or more had made no use of an outpatient facility during the preceding 12 months. Less than half the surveyed population lived in a village with a primary health care facility [7]. Less than half the population aged 80 or more reported using an 
outpatient facility (48.8\%), despite very sharp increases in poor self-reported health among this age group.

One consequence of limited service utilisation is low awareness of conditions like hypertension. National data for over 50 s in rural settings show particularly low rates of awareness ( 28 per cent compared to 38 per cent in the total population) and control (5 versus 8 per cent) [10]. Limited regular engagement with health care providers is also an important barrier to more effective control of hypertension and other common health conditions. This is particularly true for older adults in rural settings, who are more likely to be illiterate and have problems of mobility [10], and who often lack lifetime experience of engaging with health care providers [11]. Levels of hypertension treatment efficacy are low for older people in South Africa (25 per cent), possibly due to a lack of regular engagement and follow-up with a trained health worker.

As such, the key challenge this study addressed was how to improve engagement between formal health care workers and older people in rural districts of South Africa, with a particular focus on enhancing hypertension awareness through screening and reducing blood pressure by offering participants a monthly supply of low sodium salt.

The key novelty of this study is the setting of the intervention: village pension markets. South Africa has a universal old age grant, delivered on a monthly basis. The scheme covers a high proportion of older adults in rural locations [12]. Old age pensions are usually delivered to villages on a single day each month. When possible, older people collect their pensions in person and often queue for long times to do so. Working inside pension markets may offer the possibilities both of reaching older people who do not regularly attend health services and of following up with these people on a monthly basis. Alongside more orthodox service strategies, a pension market intervention may offer an effective and pro-active approach for reaching vulnerable individuals who would otherwise be excluded from provision.

As such, the study assessed the validity of engaging with older people at the point of pension delivery. This included providing information about hypertension, measuring blood pressure, providing advice on referral and providing a monthly supply of low sodium salt. We recruited 20 older people to participate in the intervention and it was conducted over three consecutive months in two villages. Towards the end of the intervention, we conducted focus groups with study participants and held a meeting with local stakeholders, including the district health office and the state social security agency.

This paper sets out the rationale and general design of the intervention and focusses on the retention of study participants and the level of support expressed by key local stakeholders. As part of the pilot, we collected data on the impact of the intervention on participant blood pressure, both as measured over time and as perceived by the participants. Given the small size of the study, these data should only be as interpreted as broadly indicative of the potential effect of such an intervention. Taken together, the study findings provide some grounds for conducting a larger-scale intervention to robustly assess potential effects on participant health. 
The study indicated that a larger-scale intervention with robust impact evaluation is feasible. There are strong grounds for this larger intervention. Across low and middleincome countries (LMICs), older populations account for a growing share of the burden of disease. Often, particularly in rural areas, they represent a hard to reach population, due to limited mobility, health awareness and literacy. Several LMICs are extending monthly pension provision to older adults in rural areas. Combining pension delivery with targeted health interventions may offer a new opportunity to reach these groups.

\section{Methods}

Of the approximately thirty pension pay points in the Agincourt study area, two were selected according to geographical criteria. Initial scoping visits were made to observe the pension markets and receive permission from the local village heads. Ten older people were recruited opportunistically by a trained researcher from people queueing at each pension pay point. The researcher, who was trained to take blood pressure readings, provided participants with information about the study. Participants' blood pressure was measured using a Boso Medistar Wrist Blood Pressure Monitor Model S. ' The researcher conducted a short baseline structured interview, assessing awareness of hypertensive status, knowledge of the condition, the extent of engagement in potentially risky behaviours, engagement with providers and use of treatment (including adherence issues). Participants were provided with information about hypertension and, in cases where they presented with an elevated blood pressure measurement, a referral letter to the closest health facility. Finally, participants were provided with a $400 \mathrm{~g}$ monthly supply of low sodium salt. In subsequent engagements, blood pressure was re-measured, and participants were asked about any changes to behaviour in response to participation in the baseline engagement, including changes to treatment seeking and risk behaviour and their use of low sodium salt. Additional low sodium salt was provided for participants who requested it (all participants did).

Towards the end of the intervention two focus group discussions (FGDs) were held with participants. These included a total of 13 participants ( 6 older men and 7 older women) from the pension market intervention. These meetings took place at the offices of the MRC/Wits Agincourt Research Unit and in a local school.ii The FGDs focussed on participants' knowledge of hypertension, including key risk factors and treatment, as well as specifically on their experience of participating in the intervention. A key objective of the FGDs was to gauge the potential willingness of participants to engage in a larger and longer version of the same intervention. The FGDs were taped and transcribed by a local research assistant. Interview transcripts were then subjected to manual coding and thematic analysis. Finally, a meeting was held with representatives of the District Health Office and Social Security Office. In this meeting, we shared anonymised findings from the intervention and gauged local officials' potential interest in supporting a larger intervention.

\section{Results}


We found a high level of retention and continued engagement among the original 20 participants. Of these, 19 continued to participate in the intervention on subsequent monthly pension days. This indicates that the intervention lends itself well to regular monthly engagement and follow-up with older people which is valuable for the management of chronic conditions such as hypertension.

Participants' knowledge of hypertension was mixed and sometimes flawed. In the focus group discussions, they referred to a wide range of symptoms and conditions which they associated with high blood pressure. These included feeling hot and bad tempered, muscular pain ("You will feel like they put a bag of maize meal on your shoulder"), itching eyes, cramps, breathlessness, constipation, hiccups, dizziness, painful legs, night sweats, blurred vision, temporary blindness, shingles, weight loss, and vomiting. They also referred to a wide range of potential risk factors. The most frequently mentioned risk factor was anger and worrying ("thinking a lot"), with mentions also made of alcohol ("Because if you are drunk you don't eat enough food. You will have a little and eat meat only. And when time goes on you will be infected by high blood pressure because you are not eating well"), diet (oily food and insufficient fruit or vegetables) and smoking. Particular reference was made to salty food, although the participants' high awareness of this may have been the result of their participation in this study. No reference was made to being obese or overweight (the main risk factor for hypertension) or to lack of exercise. It was generally understood that hypertension could lead to strokes and that the condition was a permanent one ("We are married to this high blood pressure. It will not end until death does us part").

At the start of the intervention, all the focus group participants said that they had already been taking medication to control their hypertension. Some expressed frustration that this treatment did not appear to alleviate the symptoms that they associated with high blood pressure:

What I can say is that we are taking the treatment but we don't get cured. We are always taking the treatment but we are not getting better. We don't know what to do now.

Their concerns were reflected in the findings of our baseline blood pressure measurements, which found that 13 participants had uncontrolled hypertension, despite claiming to be on treatment. One explanation was that participants were not taking medication on a daily basis, although the focus group participants, unprompted, emphasised the importance of adhering consistently to drugs regimens. However, participants observed that they sometimes faced problems accessing medication and ongoing treatment:

At the health centre they don't tell you. If you didn't look at what they have written you will not know how your blood pressure is... They only tell us when the BP is very high and tell you to come and see the doctor. And when the doctor arrives, he will give you the same treatment that you were using; nothing will change.

The last time when I went to the clinic they gave me some tablets and they told me not to come back, saying that it's my last treatment. I went to a [health centre] and 
they took blood samples and they told me that they don't have treatment. I asked them what to do and they told me to buy the medication. I tried to ask them where to buy and they said any place that I want to buy. Then I asked them if I have to come back and they said no. Then I took the paper where they have written the prescription and threw it away.... because they didn't tell me where to go, and that's the illness that troubles me.

I was sick and went to the clinic and they diagnosed me with high blood pressure.... They referred me to the hospital... They treated me at the hospital and I was fine. Then I told myself that now I don't have high blood pressure. Then I come home and relaxed. After some time I started again having the same problem. Then I was taken to the clinic and they said its high blood and if you don't take the medication you will die. Then I told them that I am taking the treatment but it's always high.

My first time to find out that I have high blood pressure, I was not feeling well and they took me to private doctor... He diagnosed me with high blood pressure and I said to him that I don't have it. He gave me the treatment and a return date but I didn't go for a check-up because I was feeling better.

There is this tablet that you tear it into half and put it on the water. I have two months without getting that tablet. When we went to the clinic, they are always telling us that they don't have the tablet.

Informants also claimed that they struggled to find or to afford fresh fruit and vegetables, which they knew to be good for their health. One older woman went as far as to suggest:

Maybe they can provide us with plants that we can plough like spinach and cabbage; then we plough it so that we can always eat food like that. We do want to plough some vegetables but we don't have money to buy the plants... If they can provide us with things to plant and grow the vegetables at home, then we eat healthy food; you will find that things are well in our body. When you are worried, it is because you don't have money to buy what you want.

There was a strong consensus among the focus group participants that the salt had eased various symptoms they associated with high blood pressure. Typical comments included:

I think my blood pressure is under control, because when I eat food that has lot of salt I will start like having difficulty in breathing, but if I use my salt correctly, when I go to bed I don't have that difficulty in breathing.... now I am able to run a little bit and eat anything because the salt is working well on me.

Nowadays I am able to sleep well without the sleepless night that I use to have, I think the salt is helping me a lot.

Since I started to use the salt, I am able to walk fast. Since I used to go to prayers, there is certain hill... that I tried myself on it. I started to run and I finish it without having difficulty in breathing or feeling anything. I also eat well without any problem, and even when I pass stools I don't have problems. 
The salt that we are using is good to me because I am able to cover myself this winter when I go to bed. I am able to wear my night dress and also cover myself with a blanket. I used to sweat a lot and have difficulty in breathing when walking. But nowadays I don't have that difficulty in breathing, it is better.

Some of things that have changed after using the salt is feeling the headache and being weak when I want to do something. Also when I'm walking, I was feeling weak and dizzy, but now I am able to chase a kid if I want to discipline that kid. I was failing to lift a $20 \mathrm{~L}$ bucket of water, but now I am able to do that.

These perceptions were, to some extent, supported by blood pressure reading data (Table 1). Of the 19 cases, 16 saw a fall in systolic blood pressure between the first and second pension market and 14 saw a fall in diastolic blood pressure (in one case it remained the same). Average systolic blood pressure fell from 150.5 to 139.1 between these two observations. Average diastolic blood pressure fell from 89.8 to 85.3 over the same period. Observations for the third pension market showed a slight rise in systolic blood pressure (to 140.6) but a continued fall in diastolic pressure (to 83.8).

\section{TABLE 1 ABOUT HERE}

None of the participants reported any problems or reluctance with using the low sodium salt, and all were very keen to continue using the product if it could be made available. Comments included:

Bring more salt to us because it is good to us. When you have used it on your food, it tastes good.

Participants were asked their opinion about the wider suitability of the project intervention and there was strong, unanimous enthusiasm. Comments included:

I think people will not feel lazy to test, because they don't have to queue until you get hungry and you get dizzy if you are at the health centre. But for you, who are in just a drop-in centre [at the pension pay point]...when you are there you find that you test us very fast before we get hungry. It is better than going to the health centre and staying on the bench the whole day. It help us a lot and we will able to be sure that as I have tested this month I am fine and I will know my readings that this month my blood pressure is this and when I went to the next pension market I will test and know that oh...its getting down; it is very good.

At the pension market it's good because even those who are lazy to go to the clinic. When they saw you there he/she will come to test and get help, because you are nearer and it is good when you go to the pension market and test people's hypertension.

If the government is failing to provide the treatment, they must tell us and when we get paid our pension we will pay Wits to provide us with the treatment. 
It is good to test us every month. People will be interested and we have lots of friends who are willing to do it now.

On my way to the FGD, I met someone who complained about high blood pressure and she ask me to share the salt with her. But I refused to give her it, because if I share with her and I finish my salt, how am I going to go on without the salt? [laughs]

The pensioners were not alone in recognising the potential of this intervention. In both focus groups, participants mentioned that hypertension services were being provided at pension pay points on an unofficial basis.

I went to him and he measured my blood pressure. And after that he told me to buy some tablets from him. He has tablets and some medication and it's very expensive.

He is working with a lady who is recruiting people. She came to recruit me and I refused, saying that I will not do that if my wife is not there... That white man who is measuring high blood pressure is from [a town], and there are lots of Afrikaners there. They will create some medication like Bosom who created some of the drugs; he will do the same to our people. If he says he is providing for free, he will give it to people and they will die.

\section{Discussion}

The results of this highly-focussed, small-scale study should not be taken as representative of a wider population. Nonetheless, they are broadly in keeping with the findings of other studies conducted in South Africa and sub-Saharan Africa. The growing awareness of hypertension as a serious health condition as reported by our participants, combined with their imperfect knowledge of the condition and how to manage it, accords with a systematic review which found high rates of prevalence of hypertension across sub-Saharan Africa, as well as low rates of awareness, treatment and control [13]. Similar findings have been reported by research conducted in different parts of South Africa [14, 15]. The difficulties participants reported in obtaining information, effective treatment and managing the condition are similar to those reported in a qualitative study of hypertensive patients in Cape Town [15].

While there may have been some placebo effect, the apparent beneficial effects of using the low sodium salt product, as reflected in both respondents' testimonies and our limited biometric data, are in line with a strong body of evidence that reduced salt consumption and/or the use of low sodium salt can significantly reduce blood pressure, and that this effect has been widely observed to occur within a single month [16, 17]. Recognising this, the World Health Organisation recommends that all countries enact legislation to compel food producers to reduce the sodium content of their products. In South Africa, this legislation has been enacted and came into effect in 2016 [18]. It is to be hoped that the legislation will prove effective, but it remains unproven and its impact may be more limited in rural areas where a larger share of food consumption is derived from the unorganised 
sector of the economy. Also, there is evidence that nearly half of salt intake in South Africa is derived from adding salt to food during cooking or eating [19].

Discussions with stakeholders from the local district health office and pensions agency demonstrated that, in principle, they are strongly supportive of the intervention and would be open to working together. That said, they raised important ethical issues about the sustainability of a pilot, a subsequent termination of the intervention and the withdrawal of free low sodium salt to pensioners. The project team are now exploring solutions to this, including working with local businesses to ensure a supply of affordable low-sodium salt post-pilot.

Most studies of hypertension interventions in South Africa have been conducted in urban settings, rather than rural ones. There is evidence that existing South African hypertension services provided through primary care providers are ineffective in modifying risk behaviours among poor urban blacks, but other modalities of service delivery have not been assessed [20]. There is also evidence that screening for hypertension at mobile units promotes linkage to care and uptake of medication, but there is no evidence of impact on control rates [21]. The use of community health workers to make home visits has been associated with higher rates of hypertension control in South Africa [22], although the limited health care infrastructure of most rural areas would reduce the feasibility of such an intervention. A number of studies claim that providing older people with cash transfers alone can enhance health outcomes, even without bundling in health interventions [23, 24]. However, other studies indicate that their impact on the control of conditions such as hypertension is insignificant [25].

The intervention in this pilot study draws on aspects of two different interventions, both conducted in South Africa. Charlton et al [26] report on an intervention that provided hypertensive subjects in Cape Town six food items with modified cation content, of which one was a similar low sodium salt product to that used in our intervention. Their intervention was done over an 8 week period and significant reductions of blood pressure were observed for the non-control group. The second study consisted of a pilot intervention to screen older people for cataracts at pension pay points [27]. The pilot intervention led to increased awareness and demand for cataract treatment, but was discontinued.

\section{Conclusions}

Across sub-Saharan Africa, the rapidly-escalating epidemic of hypertension and other noncommunicable diseases calls for research into effective interventions to be given the highest possible priority [28]. The specific nature of sub-Saharan African contexts means that interventions proven to be effective in high or middle income country settings may be less effective than hoped. Thus, there is an urgent need to develop novel approaches tailored to both the challenges and opportunities offered by different settings.

The limited findings from this pilot study indicate that combining health interventions with pension delivery is worth investigating on a larger scale. Overall, we found that participants 
demonstrated a very high level of acceptance of the low sodium salt product. Indeed, they complained about the absence of this product from local stores. These sentiments were expressed very strongly in both focus groups and in repeat uptake of the product during the monthly interventions. The pilot demonstrated the logistical feasibility for a larger study and the strong support of local stakeholders.

If proven to be effective, this intervention could be extended to improve the health of people across rural South Africa, as well as in sub-Saharan Africa and other low and middle income countries. In South Africa, the government provides over three million old age grants, with coverage particularly high among poor, rural populations. Additionally, the government provides over a million grants for disabled adults, who could potentially benefit from this intervention. Across low and middle income countries, a growing proportion of adults receive pensions, either for disability or old age. Universal old age pensions are available in Namibia, Botswana, Lesotho, Bolivia, Mexico, Brazil, Peru and other countries. Substantial targeted "social pension" schemes have been implemented in several subSaharan African countries, including Kenya, Uganda, Nigeria and Zambia [29]. These targeted schemes focus on poorer older people in rural settings: groups most likely to face challenges in managing chronic health conditions. None currently include additional health interventions along the lines of the one discussed in this paper. Finally, the intervention described in this paper could potentially be extended to manage other health conditions, as well as hypertension. In sum, if proven to be effective, this intervention, or versions of it, has the potential to significantly enhance hypertension management for millions of adults across low and middle income countries. 
Table 1: Blood pressure readings for intervention participants.

\begin{tabular}{|c|c|c|c|c|}
\hline Sex & $\begin{array}{l}\text { Visit 1- sys/dia } \\
\text { (pulse) }\end{array}$ & $\begin{array}{l}\text { Visit 2- } \\
\text { sys/dia } \\
\text { (pulse) }\end{array}$ & $\begin{array}{l}\text { Visit 3- sys/dia } \\
\text { (pulse) }\end{array}$ & $\begin{array}{l}\text { Visit 4- } \\
\text { sys/dia } \\
\text { (pulse) }\end{array}$ \\
\hline $\mathrm{F}$ & $142 / 90$ (87) & $119 / 88(74)$ & $155 / 104(65)$ & $111 / 88(80)$ \\
\hline $\mathrm{F}$ & $145 / 106(84)$ & $134 / 99(80)$ & $146 / 93(91)$ & $132 / 90(87)$ \\
\hline $\mathrm{F}$ & $214 / 112(82)$ & $\begin{array}{l}172 / 116 \\
(100)\end{array}$ & $154 / 84(95)$ & \\
\hline $\mathrm{F}$ & $132 / 86(64)$ & $134 / 75(68)$ & $127 / 80$ (77) & \\
\hline $\mathrm{F}$ & 146/85 (89) & $121 / 81$ (67) & $134 / 81$ (87) & $130 / 92$ (91) \\
\hline $\mathrm{F}$ & $149 / 80(70)$ & $130 / 75(80)$ & & \\
\hline$M$ & 151/98 (80) & $127 / 75$ (64) & $119 / 72(66)$ & $111 / 80(70)$ \\
\hline$M$ & 181/97 (69) & 151/97 (73) & $140 / 86(64)$ & $127 / 72$ (77) \\
\hline M & $145 / 94(63)$ & $132 / 112(82)$ & $130 / 77$ (68) & $135 / 68$ (91) \\
\hline$M$ & $156 / 87(62)$ & $153 / 89$ (67) & $136 / 85(72)$ & $143 / 67$ (87) \\
\hline $\mathrm{F}$ & 174/93 (68) & & $161 / 84$ (67) & \\
\hline$M$ & $177 / 98$ (67) & $161 / 85$ (67) & $138 / 70(66)$ & \\
\hline $\mathrm{F}$ & $112 / 77$ (65) & $160 / 67$ (67) & $144 / 88(90)$ & \\
\hline M & 132/79 (70) & $125 / 80(84)$ & $146 / 84$ (81) & $112 / 66$ (88) \\
\hline $\mathrm{F}$ & $156 / 93(105)$ & $133 / 90$ (87) & $148 / 88$ (99) & $130 / 80(66)$ \\
\hline $\mathrm{F}$ & 133/81 (74) & $144 / 78(96)$ & $141 / 88$ (77) & $106 / 90(66)$ \\
\hline $\mathrm{F}$ & 144/91 (95) & $132 / 89$ (90) & $147 / 95$ (87) & $127 / 89(90)$ \\
\hline$M$ & $132 / 89$ (90) & $125 / 75(82)$ & $124 / 81$ (69) & $130 / 67(80)$ \\
\hline$M$ & $138 / 70(66)$ & $129 / 65(70)$ & $140 / 68(64)$ & \\
\hline
\end{tabular}




\section{Declarations Section.}

\section{List of abbreviations.}

HDSS Health and Socio-Demographic Surveillance System

\section{Ethics approval and consent to participate.}

Ethical clearance for the study was obtained from both the Human Research Ethics Committee of the University of Witwatersrand (protocol number M160249) and Mpumalanga Provincial Health

Research and Ethics Committee.

\section{Consent for publication.}

Not applicable.

Competing interests.

The authors declare that they have no competing interests.

\section{Authors' contributions.}

All authors read and approved the final manuscript.

PLS, ST and FGO led the conception and design of the intervention study.

$\mathrm{SN}$ and RW led the conduct of the intervention and acquisition of data.

PLS led the interpretation of data and drafting the manuscript.

\section{Availability of data and material.}

Fully anonymised datasets analysed during the current study available from the corresponding author on reasonable request.

\section{Acknowledgements.}

We are grateful to Rhian Twine (MRC/Wits Rural Public Health and Health Transitions Research Unit, Agincourt), who arranged and facilitated the stakeholder discussion.

\section{Funding.}

Funding was provided by the UK's Economic and Social Research Council (grant ES/P003516/1), the University of East Anglia and the University of Witwatersrand. 


\section{References.}

[1] Ibrahim MM, Damasceno A. Hypertension in developing countries. Lancet. 2012; 380:611-619.

[2] He FJ, MacGregor GA Salt intake and mortality. Am J Hypertens. 2014; 27(11):1424

[3] Whelton PK, Appel LJ Sodium and cardiovascular disease: what the data show. Am J Hypertens. 2014; 27(9):1143-5.

[4] Noubiap JJ, Bigna JJ, Nansseu JR Low sodium and high potassium intake for cardiovascular prevention: evidence revisited with emphasis on challenges in sub-Saharan Africa. Journal of Clinical Hypertension 2015; 17(1):81-3.

[5] Lloyd-Sherlock P, Beard J, Minicuci $\mathrm{N}$ et al Hypertension among older adults in low and middle income countries: prevalence, awareness and control. International Journal of Epidemiology 2014; 14(1):116-128.

[6]. Bertram MY, Steyn K, Wentzel-Viljoen E, et al Reducing the sodium content of high-salt foods: effect on cardiovascular disease in South Africa. South African Medical Journal 2012; 102(9):743-5.

[7] Gómez-Olivé FX, Thorogood M, Clark B, Kahn K, Tollman S. Self-reported health and health care use in an ageing population in the Agincourt sub-district of rural South Africa. Global Health Action 2013; 24(6):19305.

[8] Kahn K, Tollman SM, Collinson MA, et al. Research into health, population and social transitions in rural South Africa: data and methods of the Agincourt Health and Demographic Surveillance System. Scand J Public Health Suppl 2007; 69:8-20.

[9] Gómez-Olivé FX, Thorogood M, Bocquier P, Mee P, Kahn K, Berkman L, Tollman S. Social conditions and disability related to the mortality of older people in rural South Africa. International Journal of Epidemiology 2014; 43(5):1531-41.

[10] Gómez-Olivé F, Thorogood M, Clark BD, et al Assessing health and well-being among older people in rural South Africa. Glob Health Action 2010; Supplement 2:23-35.

[11] Albanese E, Liu Z, Acosta D, et al Equity in the delivery of community healthcare to older people: findings from 10/66 Dementia Research Group cross-sectional surveys in Latin America, China, India and Nigeria. BMC Health Services Research 2011; 11:153.

[12] Woolard I. Harttgen, K \& Klasen, S The evolution and impact of social security in South Africa. Southern African Labour and Development Research Unit, University of Cape Town. 2010 http://erd.eui.eu/media/BackgroundPapers/Woolard-Harttgen-Klasen.pdf [accessed 18.9.16].

[13] Ataklte F, Erqou S, Kaptoge $S$, et al Burden of undiagnosed hypertension in sub-Saharan Africa: a systematic review and meta-analysis. Hypertension 2015; 65(2):291-8. 
[14]. Adebolu F and Naidoo M Blood pressure control amongst patients living with hypertension presenting to an urban district hospital outpatient clinic in Kwazulu-Natal. African Journal of Primary Health Care and Family Medicine 2014; 6(1):E1-6.

[15] Murphy K, Chuma T, Mathews C, Steyn K and Levitt N A qualitative study of the experiences of care and motivation for effective self-management among diabetic and hypertensive patients attending public sector primary health care services in South Africa. BMC Health Services Research 2015; 15:303.

[16] Adler AJ, Taylor F, Martin N, et al Reduced dietary salt for the prevention of cardiovascular disease The Cochrane Database of Systematic Reviews 2011;CD009217.

[17] He F, Li J \& Macgregor G. Effect of longer-term modest salt reduction on blood pressure. The Cochrane Database of Systematic Reviews 2013; 4:CD004937.

[18] Sookram C, Munodawafa D, Phori PM, et al WHO's supported interventions on salt intake reduction in the sub-Saharan Africa region. Cardiovascular Diagnosis and Therapy 2015; 5(3):186-90.

[19] Charlton KE, Steyn K, Levitt NS, et al Diet and blood pressure in South Africa: Intake of foods containing sodium, potassium, calcium, and magnesium in three ethnic groups. Nutrition 2005; 21(1):39-50.

[20]. Dennison CR, Peer N, Lombard CJ, et al Cardiovascular risk and comorbid conditions among Black South Africans with hypertension in public and private primary care settings: the HiHi study. Ethnicity and Disease 2007; 17(3): 477-83.

[21] Govindasamy D, Kranzer K, van Schaik N, et al Linkage to HIV, TB and noncommunicable disease care from a mobile testing unit in Cape Town, South Africa. PloS One 2013; 8(11): e80017.

[22] Ndou T, van Zyl G, Hlahane S and Goudge J A rapid assessment of a community health worker pilot programme to improve the management of hypertension and diabetes in Emfuleni sub-district of Gauteng Province, South Africa. Global Health Action 2013; 6:19228.

[23] Case, A., \& Wilson, F Health and wellbeing in South Africa: Evidence from the Langeberg survey. Princeton University. 2000.

https://www.princeton.edu/ accase/downloads/Health and Wellbeing in South Africa e vidence Langeberg survey.pdf [accessed 19.9.16].

[24] Schatz E, Gómez-Olivé X, Ralston M, et al The impact of pensions on health and wellbeing in rural South Africa: does gender matter? Social Science and Medicine 2012; 75(10):1864-73.

[25] Lloyd-Sherlock, P and Agrawal, S Pensions and the health of older people in South Africa. Is there an effect? Journal of Development Studies 2014; 50(11):1570-1586. 
[26] Charlton KE, Steyn K, Levitt NS et al A food-based dietary strategy lowers blood pressure in a low socio-economic setting: a randomised study in South Africa. Public Health Nutrition 2008; 11(12), 1397-1406.

[27] Rotchford, A. \& Johnson, G Rapid assessment of cataract surgical coverage in rural Zululand. South African Medical Journal 2000; 90(10), 1030-32.

[28] Pearce N, Ebrahim S, McKee M et al Global prevention and control of NCDs: Limitations of the standard approach. Journal of Public Health Policy 2015; 36(4):408-25.

[29] Guven M and Leite P Benefits and Costs of Social Pensions in Sub-Saharan Africa. World Bank, Social Protection and Labor Discussion Paper, Number 1607. 2016;

http://documents.worldbank.org/curated/en/325281469593828257/Benefits-and-costs-ofsocial-pensions-in-Sub-Saharan-Africa [accessed 19.9.16].

[30] O'Brien E, Asmar R, Beilin L, et al European Society of Hypertension recommendations for conventional, ambulatory and home blood pressure measurement Journal of Hypertension 2003; 21:821-848

\footnotetext{
'Blood pressure measurements were taken in accordance with international guidelines [30].

ii All 20 participants from the pension market intervention were invited, but 7 were not available at the scheduled time for the FGDs.
} 